\title{
Influence of Polymer Matrix Based on Mixtures of Cellulose Diacetate and Polyvinyl Formal on Kinetics of Complex Formation of $\mathrm{Zn}^{\text {II }}$ with Tetraphenylporphine
}

\author{
Pavel V. Singin, ${ }^{a}$ Irina P. Trifonova, ${ }^{\circledR a}$ Vladimir A. Burmistrov, ${ }_{1}^{\mathrm{a}, \mathrm{b}}$ \\ and Oscar I. Koifman ${ }^{a, b}$
}

${ }^{a}$ Research Institute of Macroheterocyclic Compounds, Ivanovo State University of Chemistry and Technology, 153000

Ivanovo, Russia

'Institute of Solution Chemistry of Russian Academy of Sciences, 153045 Ivanovo, Russia

${ }^{@}$ Corresponding author E-mail: trifonova@isuct.ru

\begin{abstract}
Influence of polymer matrix based on mixtures of cellulose diacetate and polyvinyl formal on kinetics of Zn tetraphenylporphine complex formation was studied. Basic kinetic and diffusion characteristics of the process were measured. Decisive influence of polymer matrix rigidity on porphyrin reactivity was found.
\end{abstract}

Keywords: Porphyrin, complex formation, membranes, cellulose diacetate, polyvinyl formal.

\section{Introduction}

Reactivity of both natural and synthetic porphyrins depends on nature of solvation interactions in solutions and polymer matrices. Presence of various reaction centers in macroheterocycle molecules provides the possibility of porphyrin-solvent specific interactions, which determine different reactivity of porphyrin in various media. ${ }^{[1]}$

Previously in work, ${ }^{[2]}$ reactivity of tetraphenylporphine $\left(\mathrm{H}_{2} \mathrm{TPP}\right)$ incorporated in cellulose diacetate (CDA) membrane was determined by hindrance of rigid-chain polymer matrix on macroheterocycles deformation, and that did not depend on diffusion rate of aqueous solutions of zinc and cadmium acetates. Increasing of swelling degree of CDA in water-ethanol mixtures in the range $10-40 \%$ is accompanied by acceleration of metalloporphyrin formation by five orders of magnitude.

This fact is consistent with scheme of metalloporphyrin formation, ${ }^{[3]}$ in which deformation of macrocycle plays a crucial role. Thus, changing conditions of solvation at the transition from low-molecular solvent to polymer matrix and then to polymer matrix based on a mixture of two polymers with different hydrophilic properties, it is possible to identify the factors that strongly influence on the kinetics of complex formation.

\section{Experimental}

Diffusion membranes based on regular hydrophilic polymer CDA (secondary cellulose acetate, the manufacturer - company «Phöne-poulenc») and polyvinyl formal (PVF, obtained from polyvinyl alcohol; molar content of vinyl formal units $68.7 \%$, vinyl alcohol units $27.2 \%$, vinyl acetate units $4.1 \%$ ) obtained by dry spinning. ${ }^{[4]}$ Content of PVF varied from $100 \%$ to $60 \%$ (by weight of polymer). A lower content of PVF, up to $20 \%$, does not allow to obtain homogeneous film. The thickness of obtained membrane was measured using a thickness meter with an accuracy of 0.5 microns.

Spectral analysis in the UV and visible regions indicates the molecular-dispersed state of $\mathrm{H}_{2} \mathrm{TPP}$, as evidenced by implementation of Lambert-Beer law. Electronic absorption spectra were recorded on a Perkin - Elmer "UV/VIS Lambda 20" scanning spectrophotometer with a setting accuracy of wavelength \pm 0.1 $\mathrm{nm}$. Thermostatic attachment "Peltier" was used for measurements at different temperatures with an accuracy of $0.15{ }^{\circ} \mathrm{C}$. All measurements were performed in $0.2 \mathrm{~cm}$ and $1 \mathrm{~cm}$ standard quartz cuvettes. Computer program developed by Ocheretovy A.S. ${ }^{[5]}$ was used to calculate rate constants of reaction. This program based on the using of absorbance measurements in the maximum possible number of points of spectra series, obtained by means of spectrophotometer which provides automatic digital recording. The error in determining of reaction rate constants did not exceed $7 \%$.

Swelling (sorption) of polymer films was studied in water vapor atmosphere (at $100 \%$ humidity and $\mathrm{T}=298 \mathrm{~K}$ ) by gravimetric method using an analytical balance VLR-200. Previously films were dried in an exsiccator over phosphorus pentoxide at $\mathrm{rt}$ until constant weight. Quantitative characteristic of the swelling was swelling (sorption) degree ( $\alpha, \%)$, calculated by Equation (1):

$$
\alpha=\left(\mathrm{m}-\mathrm{m}_{0}\right) / \mathrm{m}_{0} \cdot 100 \%
$$

The permeability coefficient of membranes was measured by electrical conductivity. Platinum electrode in addition to immittance meter LCR-817 was used to measure the resistance of zinc acetate solutions. The relative error of concentration did not exceed $5 \%$. Amount of passing through membrane substance was determined by calibration dependence of test solutions resistance on their concentration.

Before kinetics and diffusion studies the polymeric membranes were kept in distilled water for five hours at a temperature of $298 \mathrm{~K}$, because time necessary to reach equilibrium swelling degree is approximately 5 hours for both modified and unmodified polymeric membranes. Further, by means measuring the resistance of studied solutions, amount of salt passed through membrane for a certain period of time was determined.

Value of $\mathrm{dQ} / \mathrm{dt}$ was calculated from the straight-line part (stationary process) of dependences $\mathrm{Q}=f(\mathrm{t})$, then permeability coefficient $P$ was determined according to Fick's equation: ${ }^{[6]}$

$$
P=\mathrm{Q} \cdot \delta /(\mathrm{t} S \cdot C)
$$


where $\mathrm{Q}$ - the amount of salt passing through the membrane, mole; $P$ - permeability coefficient, $\mathrm{m}^{2} / \mathrm{s} ; \delta$ - thickness of films, $\mathrm{m} ; S$ - film area, $\mathrm{m}^{2} ; C$ - salt concentration, $\mathrm{mol} / \mathrm{l}, \mathrm{t}-$ time, $\mathrm{s}$.

Half-time diffusion was calculated based on amount of salt passed through membrane during the time $t$ according to Equation 3:

$$
\mathrm{t}^{\mathrm{D}}{ }_{1 / 2}=\mathrm{t} \cdot \delta \cdot \rho \cdot S /\left(4 \cdot \mathrm{Q} \cdot M_{\mathrm{M}(\mathrm{OAc}) 2}\right)
$$

where $\mathrm{t}$ - time, $\mathrm{s} ; \delta$ - thickness of film, $\mathrm{cm} ; \rho$ - density of the solution, $\mathrm{g} / \mathrm{cm}^{3} ; S$ - film area, $\mathrm{cm}^{2} ; \mathrm{Q}-$ amount of moles of salt passed through membrane at time t, mol; $M$ - molecular weight of salt.

The error in determining the permeability coefficient does not exceed $5 \%$

\section{Results and Discussion}

Complex formation kinetics of zinc acetate $\left(\mathrm{Zn}(\mathrm{OAc})_{2}\right)$ with $\mathrm{H}_{2}$ TPP incorporated in polymer matrix based on polymer mixtures PVF - CDA was investigated. Electronic absorption specra for the modified polymer membranes in contact with $\mathrm{Zn}(\mathrm{OAc})_{2}$ aqueous solution were recordered. It was found that obtained spectra pattern was not different from behavior of spectra of $\mathrm{H}_{2}$ TPP during complexation in solution and CDA membranes. ${ }^{[2]}$ Calculation of the observed rate constant $\left(k_{\mathrm{obs}}\right)$ was carried out for complexation reaction (4):

$$
\mathrm{Zn}(\mathrm{AcO})_{2}+\mathrm{H}_{2} \mathrm{TPP} \rightarrow \mathrm{ZnTPP}+2 \mathrm{AcOH}
$$

Table 1. Reaction rates and activation parameters of interaction reaction of $\mathrm{H}_{2} \mathrm{TPP}$ with $\mathrm{Zn}(\mathrm{AcO})_{2}$ in $\mathrm{PVF}-\mathrm{CDA}$ membranes $\left(\mathrm{H}_{2} \mathrm{TPP}\right.$ content 0.6 wt.\%).

\begin{tabular}{lcccccccc}
\hline & $\delta, \mu \mathrm{m}$ & $\begin{array}{c}C\left(\mathrm{Zn}(\mathrm{OAc})_{2},\right. \\
\mathrm{mol} / \mathrm{l}\end{array}$ & $\begin{array}{c}k_{\mathrm{obs}} \cdot 10^{4}, \\
\mathrm{~s}^{-1}\end{array}$ & $\begin{array}{c}k_{\mathrm{v}} \cdot 10^{3}, \\
\mathrm{l} / \mathrm{mol} \cdot \mathrm{s}\end{array}$ & $\Delta G^{\#}, \mathrm{~kJ} / \mathrm{mol}$ & $E_{\mathrm{a}}, \mathrm{kJ} / \mathrm{mol}$ & $\Delta H^{\#}, \mathrm{~kJ} / \mathrm{mol}$ & $\Delta S^{\#}, \mathrm{~J} /(\mathrm{mol} \cdot \mathrm{K})$ \\
\hline PVF (100\%) & 49.4 & 0.0139 & 8.39 & 60.3 & 79.9 & 39.6 & 37.1 & -143.5 \\
PVF (90\%) & 53.0 & 0.0093 & 2.57 & 27.6 & 81.8 & 69.4 & 66.9 & -50.0 \\
PVF (80\%) & 54.9 & 0.0113 & 1.54 & 13.7 & 83.6 & 55.7 & 53.2 & -102.0 \\
PVF (70\%) & 53.1 & 0.0114 & 1.93 & 16.9 & 83.0 & 64.5 & 62.0 & -70.7 \\
PVF (60\%) & 66.0 & 0.0087 & 1.69 & 19.5 & 82.7 & 89.7 & 87.2 & 15.0 \\
PVF (20\%) & 43.6 & 0.0357 & 0.54 & 1.5 & 89.0 & 25.1 & 22.6 & -223.0 \\
PVF (10\%) & 44.17 & 0.0332 & 0.39 & 1.2 & 89.7 & 26.5 & 24.0 & -220.4 \\
CDA(100\%) & 43.7 & 0.0186 & 0.25 & 1.3 & 89.3 & 44.5 & 42.0 & -158.6 \\
\hline
\end{tabular}

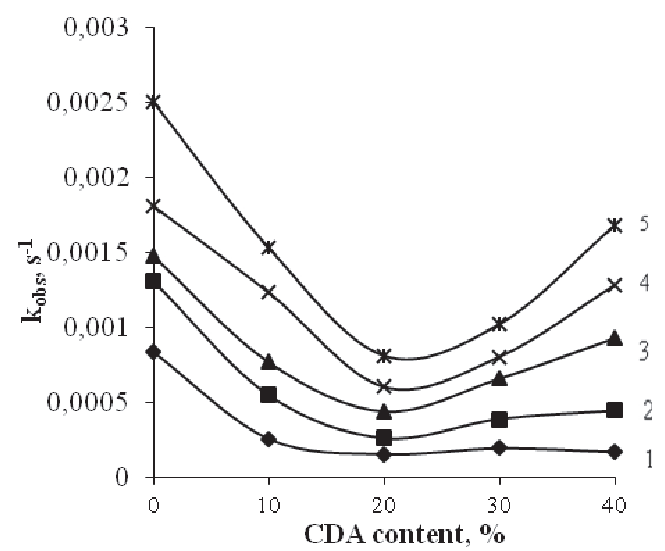

a

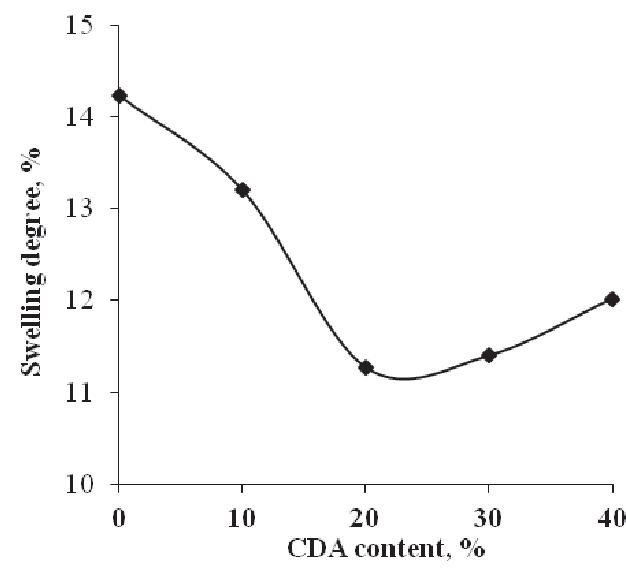

c

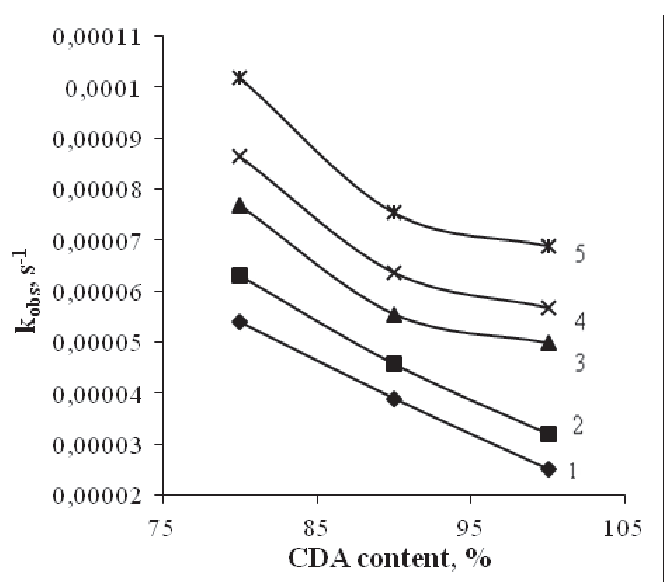

$\mathrm{b}$

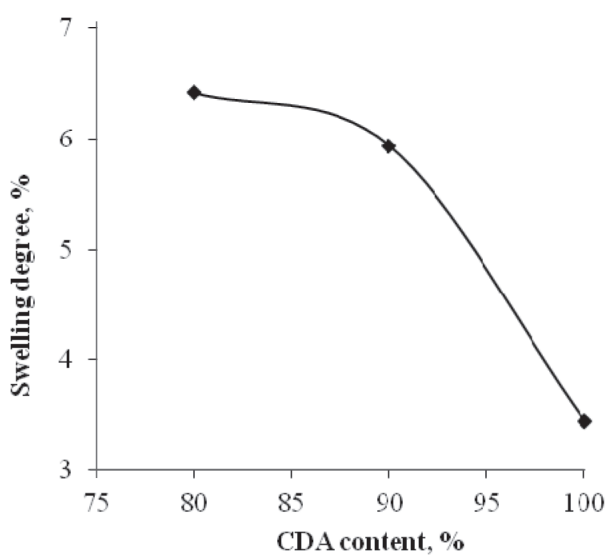

d

Figure 1. Dependence of rate constants at different temperatures (a, b) and the swelling degree at $298 \mathrm{~K}$ (c, d) for modified PVF-CDA -membranes (content $\mathrm{H}_{2}$ TPP 0.6 wt.\%) on CDA content. $1-298 \mathrm{~K}, 2-303 \mathrm{~K}, 3-308 \mathrm{~K}, 4-313 \mathrm{~K}, 5-318 \mathrm{~K}$. 
The kinetic data (Table 1 and Figure 1a, b) indicate that composition of polymer matrix significantly effect on reaction rate. Maximum values of rate constants correspond to $100 \%$ content of PVF and a minimum values $-100 \%$ content of CDA. Reaction rate constant is extremely changed with increasing of CDA content from $0 \%$ to $40 \%$, a minimum corresponds to $20-30 \%$ of CDA content. Dependence of swelling degree on composition of membranes has the same character (Figure 1c, d).

In order to identify the factors that most affect on rate constant the half-time diffusion $\mathrm{t}^{\mathrm{D}}{ }_{1 / 2}$ was calculated from diffusion experiment and the reaction half-time $t^{k}{ }_{1 / 2}=2 \ln / k_{\text {obs }}$ was calculated from kinetic experiment. The results are presented in Table 2 .

Table 2. Permeability coefficients, reaction half-times of $\mathrm{H}_{2} \mathrm{TPP}$, half-times diffusion of $\mathrm{Zn}(\mathrm{OAc})_{2}$ in modified polymeric matrices PVF- CDA, $\left(\mathrm{H}_{2} \mathrm{TPP}\right.$ content $\left.0.6 \mathrm{wt} . \%\right)$ at $\mathrm{T}=298 \mathrm{~K}$.

\begin{tabular}{ccccc}
\hline & $k_{\text {obs }} \cdot 10^{4}, \mathrm{~s}^{-1}$ & $P \cdot 10^{12}, \mathrm{~m}^{2} / \mathrm{s}$ & $\mathrm{t}^{k}{ }_{1 / 2}, \mathrm{~s}$ & $\mathrm{t}_{1 / 2}^{\mathrm{D}}, \mathrm{s}$ \\
\hline PVF (100\%) & 8.39 & 3.80 & 826 & 248 \\
PVF (90\%) & 2.57 & 3.20 & 2697 & 285 \\
PVF (80\%) & 1.54 & 2.76 & 4501 & 339 \\
PVF (70\%) & 1.93 & 2.52 & 3591 & 374 \\
PVF (60\%) & 1.69 & 2.40 & 4101 & 887 \\
PVF (10\%) & 0.39 & 0.048 & 17773 & 3781 \\
CDA (100\%) & 0.25 & 0.004 & 27726 & 18474 \\
\hline
\end{tabular}

The coefficient of permeability $(P)$ decreases and the half-time diffusion $\left(\mathrm{t}^{\mathrm{D}}{ }_{1 / 2}\right)$ increases with increasing of CDA content in the polymer membrane. Composition of the polymer matrix has much greater influence on the value $\mathrm{t}^{k}{ }_{1 / 2}$ : compared to "pure" PVF reaction half-time increases by 3-5 times. Data in Table 2 indicate that for investigated samples the diffusion rate is much higher than reaction rate of complex formation.

Thus, changing composition of polymer matrix, we can regulate swelling degree of polymer membrane and thus affect the reaction rate of complex formation (Figure 2). With an increase in 4 times of swelling degree the reaction

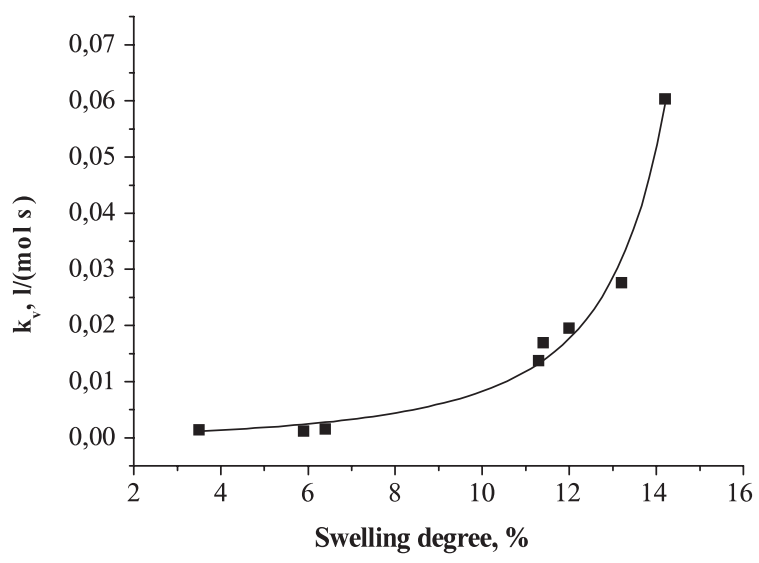

Figure 2. Dependence of the rate constant on swelling degree at $298 \mathrm{~K}$ for modified PVF-DCA membranes (content $\mathrm{H}_{2}$ TPP 0.6 wt.\%)

rate increases by 40 times. This fact confirms the initial assumptions about decisive influence of steric hindrance of rigid-chain polymer matrix on macrocycle deformation and reaction rate of metallation.

Acknowledgments. This work was supported by program of Department of Chemistry and Materials Science of Russian Academy of Sciences № 7 .

\section{References}

1. Koifman O.I., Trifonova I.P., Burmistrov V.A. J. Porphyrins Phthalocyanines 2008, 12, 404.

2. Trifonova I.P., Kononov V.D., Burmistrov V.A., Koifman O.I. Russ. J. Phys. Chem. A 2011, 85, 684-688.

3. Lavallee D.K. Coord. Chem. Rev. 1985, 61, 55-96.

4. Dubyaga V.P., Perepechkin L.P., Katalevskiy E.E. Polimernye membrany [Polymer Membranes]. Moskva: Khimiya. 1981, 232 p. (in Russ.).

5. Ocheretovy A.S., Trifonova I.P. Izv. Vyssh. Uchebn. Zaved., Khim. Khim. Tekhnol. 2007, 50, 20-22 (in Russ.).

6. Reitlinger S.A. Pronitsaemost' polimernykh materialov [Permeability of Polymer Materials]. Moskva: Khimiya. 1974, 268 p. (in Russ.) 